Applied Psycholinguistics 23 (2002), 209-231

Printed in the United States of America

DOI: 10.1017.S0142716402002035

\title{
Morphosyntactic forms of African American English used by young children and their caregivers
}

\author{
JULIE A. WASHINGTON and HOLLY K. CRAIG \\ University of Michigan
}

ADDRESS FOR CORRESPONDENCE

Julie A. Washington, University of Michigan, 1111 E. Catherine St., Ann Arbor, MI 48109-2054.

E-mail: julieaw@umich.edu

\begin{abstract}
The study of African American English (AAE) has been historically focused on the dialectal variations of adolescent and adult speakers. More recent investigations of dialect used by very young AAE speakers were undertaken with the goal of describing the language produced by early elementary and preschool-aged children. One important outcome of these studies is increased attention to the importance of considering the impact of developmental influences in our characterizations of dialect use. In this study we explore the differences between primary caregivers and their young children in dialect use across generations by directly examining the dialectal variations apparent during play interactions between primary caregivers and their young children. We conclude that there is indeed evidence in these interactions of differences between the child and caregiver in the structure and use of individual AAE features. Another conclusion is that there are many similarities in the distribution of AAE between these older and younger interactants, highlighting not only their kinship ties but also their membership in the same linguistic community.
\end{abstract}

African American English (AAE) is a major dialect system spoken by most African American adults and children in the United States (Battle, 1993; Smitherman, 1998; Washington \& Craig, 1998). Investigations of AAE span more than 30 years and have contributed greatly to our knowledge of this major American English dialect, providing us with a rich corpus of examples that represent AAE usage, as well as some of the rules governing these forms (Dillard, 1972; Fasold \& Wolfram, 1970; Labov, 1970, 1972; Wolfram, 1986; Wolfram \& Fasold, 1974). Mufwene and colleagues (Mufwene, Rickford, Bailey, \& Baugh, 1998) recently presented a comprehensive treatment of the structure, history, and current use of AAE.

Investigations of AAE have historically focused on the productions of adolescent and adult dialect users. In the case of the adult these investigations provided great insight into the characteristics of the mature linguistic system. The documentation of adolescent dialectal variation was used to make a case for the

(C) 2002 Cambridge University Press 0142-7164/02 \$9.50 
continued development of the dialect system that is apparent from the teenage years through later adulthood (approximately 60 or 70 years of age). These students provided evidence of the phenomenon called age grading, in which systematic differences in the frequency of use and structural and semantic characteristics of the dialect used by older and younger speakers are apparent and repeated in each generation (Labov, 1966; Rickford, 1992; Rickford \& Theberge Rafal, 1996). For example, Rickford (1992) and Rickford, Ball, Blake, Jackson, and Martin (1991) identified differences in the preferred use of selected AAE dialect types by their teenage subjects compared to their mothers and to much older, unrelated adults. For most dialect types the teens showed a significantly increased use of nonstandard forms, whereas their mothers and older adults demonstrated a decreased use of the same forms in their spontaneous speech. Only one feature, absence of plural $-s$, evidenced no differences in frequency of occurrence by age (Rickford et al., 1991). The significantly increased production of selected dialect forms by adolescent speakers is believed to be socially driven and is primarily explained as a means by which teenagers assert their ethnicity and youthfulness.

Among linguistic theorists there is a paucity of linguistic research directed toward understanding the dialect used by children younger than adolescents or preadolescents, which is primarily due to the goals of this line of research. These studies focused on demonstrating the systematic, rule-governed nature of AAE and, as Wolfram (1994) suggested, they provided the impetus for professionals outside the field of linguistics to address the issue of language diversity and its varied impact. These early efforts to document the legitimacy of AAE necessarily relied on speakers whose nondialectal language systems were mature in order to provide a stable linguistic base for examining dialect production without the confounding influence of developmental variations. However, the presence of robust age-grading effects in adolescent and preadolescent dialect speakers compared to adults suggests that the study of younger child speakers may be necessary to fully characterize AAE. Child language research demonstrated rather clearly that the language used by adults cannot be assumed to characterize the productions of young children. Rather, we must study young children to understand them. Unlike the time when many of these earlier studies of AAE were completed, a large and varied body of literature now exists that is focused on older speakers of AAE for potential comparison and interpretation of child linguistic data.

In recent years there has been increased attention to the characterization of dialect used by younger (elementary and preschool aged) AAE speakers in disciplines such as speech and language pathology, linguistics, and education (Craig, 1996; Delain, Pearson, \& Anderson, 1985; Delpit, 1995; Seymour, Bland-Stewart, \& Green, 1998; Washington, 1996; Washington \& Craig, 1994, 1998; Washington, Craig, \& Kushmaul, 1998). The primary goal of these investigations was to describe the speech and language produced by young African American children in order to improve our ability to design and deliver educational and clinical services. Specifically, the role of language diversity in the development of reading skills and reading instruction and the importance of distinguishing language differences from deficits in dialect speakers were of particular interest. 
An important outgrowth of this work is an increased awareness of the need to consider developmental aspects of dialect. In our own work (Washington \& Craig, 1994, 1998; Washington et al., 1998) we found that several of the morphosyntactic AAE forms identified for adolescents and adults are not evident in the language of young 4- to 6-year-old subjects. In addition, forms shared by adults and children such as double modals are produced by children using earlier, comparable linguistic structures, in particular, the double auxiliary (e.g., "I'm am") compared to the more mature structures using double modals (e.g., "I might can") that is documented in the literature for adults.

The developmental nature of language would suggest that the adult language user may evidence forms and functions not witnessed in a young speaker and that the young speaker will use language in ways that an adult will not. The purpose of this investigation was to provide a systematic description of the morphosyntactic dialect forms used by very young children (4-6 years) compared to mature language users, in this case, the primary caregivers of these young children. We considered that, because they are the childrens' language models, we could expect the dialect used by these caregivers to be representative of the mature dialect system that may ultimately develop in these young children, notwithstanding the possible effects of dialect divergence or convergence that has received so much attention in dialect research (Bailey \& Maynor, 1989; Hedges \& Nowell, 1998; Labov, 1981; Rickford, 1992; Wolfram, 1987).

Past studies of caregiver-child communicative interactions for both minority and nonminority children were largely focused on the nature of the interactions that occur between mothers and their infants or preschool-aged children. The role of the mother's input and interactive style on the child's development of a range of skills, including syntax (Menyuk, 1992; Menyuk, Liebergott, \& Schultz, 1995), conversation (Black \& Logan, 1995; Bloom, Rocissano, \& Hood, 1976; Menyuk, 1988), lexical development (Blake, 1994; Choi, 2000; Cross, 1977; Menyuk, 1992), and cognition (Murray \& Hornbaker, 1995; Ramey, Farran, \& Campbell, 1979), were investigated. These investigations determined that, although the caregiver's input did not specifically influence the development of syntax, the use of child-directed speech was facilitative for other aspects of language and cognitive growth, including lexical development.

Studies of the specific caregiver-child interactions of African American caregivers and children mirrored the focus for nonminority children and extended the work to include information concerning the impact of cultural differences on maternal communication style. These outcomes were compared to those identified for nonminority caregiver-child research and reported similar findings relative to the mother's influence on the cognition, communication, and learning of her young child for middle class African American families (Blake, 1993, 1994; Ramey et al., 1979; Wallace, Roberts, \& Loder, 1998). To date, none of these investigations has addressed dialect use by African American caregivers compared to their children. This is somewhat surprising because it would seem that the influence of cultural factors on communicative interactions is nowhere more apparent than in the cultural dialect favored by the linguistic community. For children no context may be more important for discovering these relationships than the caregiver-child interaction. 
A comparison of caregiver-child dialect use should extend the current knowledge of AAE by aiding in the interpretation of the forms produced by children relative to their community. In addition, examining dialect use during a caregiver-child interaction should both improve our ability to directly relate the findings to currently available literature on dialectal variation in adult AAE users and provide some specific insights into the linguistic similarities and differences displayed by African American mothers and their children. The following questions were posed:

1. Are there systematic differences between adults and children in their use of AAE forms?

2. What are the similarities and differences between caregiver and child uses of AAE?

\section{METHOD}

\section{Participants}

The participants were 28 African American boys $(n=15)$ and girls $(n=13)$ and their primary caregivers $(n=28)$. The children ranged in age from 52 to 85 months $(M=71$ months, $S D=10.5)$ of age and were enrolled in preschool $(n=8)$, kindergarten $(n=9)$, or first grade $(n=11)$ in the same metropolitan Detroit public school system. African American children comprised more than $80 \%$ of the student body in this urban school district, mirroring the African American concentration in the community. Most of the primary caregivers were the mothers of the participants $(n=25)$, but a small number were grandmothers $(n=3)$ with whom the children resided. All the caregivers were African American and female. A total of 117 African American children participated in data collection sessions conducted in the school buildings. Although 32 of those families consented to have their children participate in this investigation, 4 of the children were enrolled in special education services and were not included.

Most of the participants $(n=22)$ were from middle income households. The remaining six were from low income households as defined by the federal freeor reduced-price lunch program (United States Department of Agriculture, 1999). The overrepresentation of children from middle income homes in this investigation was not unexpected. Studies of informed consent have found that children from low income backgrounds are least likely to return consent forms that agree to participate in research studies (Anderman, Cheadle, Curry, \& Diehr, 1995; Ellickson, \& Hawes, 1989; Weinberger, Tublin, \& Ford, 1990). Further, the number of families considered to be at risk, such as those from low income homes, that agree to participate in research studies involving visits to their homes is smaller still (Weinberger et al., 1990). These trends are reflected in the socioeconomic composition of our participants.

\section{Data collection}

An African American female examiner went to the home of each child subject for the data collection sessions in order to facilitate the collection of spontaneous, free play language samples during adult-child discourse involving the care- 
giver and child. Whenever possible, the examiner set up the equipment and toy sets and then was not present during the caregiver-child interaction. At other times she remained in the background and read silently.

Each caregiver and child wore individual head microphones, and language samples were audiorecorded using an audiotape recorder and microphone mixer in a quiet room in the child's home. Sample durations were approximately 20 $\min (M=20.8 \mathrm{~min}, S D=1.82 \mathrm{~min})$ in length. Each child was presented with three action toy sets and allowed to select one for play in an attempt to standardize interest levels in the play materials across participants. The toy sets included Barbie $^{\mathrm{TM}}$ and $\mathrm{Ken}^{\mathrm{TM}}$ dolls with a Burger King ${ }^{\mathrm{TM}}$ play set, Ninja Turtle ${ }^{\mathrm{TM}}$ action figures and props, and the Fisher-Price ${ }^{\mathrm{TM}}$ School. The choices were successful in maintaining the interest of each child. At the end of the taping session the examiner returned to indicate that the session was finished.

\section{Transcription and scoring}

The language samples were transcribed orthographically using the CHAT conventions of the Children's Data Exchange System (CHILDES; MacWhinney, 1994). Transcripts were scored for the occurrence of one or more AAE types (the different AAE forms identified) and AAE tokens (total AAE forms produced) using our definitions (Washington \& Craig, 1994, 1998) for children. The forms are morphosyntactic in nature and are the core features for AAE, regardless of the phonological variations, which are influenced by regional dialects. Our earlier work identified morphosyntactic AAE types from the discourse of children from low and middle socioeconomic status (SES) homes. The Appendix provides examples of these same AAE types obtained from the samples of the children and adults who participated in the present investigation. Following coding, AAE types and tokens were extracted from the transcripts using the Computerized Language Analysis program designed for use with CHILDES transcriptions.

In addition to the morphosyntactic AAE types identified for children in our earlier work (Washington \& Craig, 1994), the adult and child transcripts were both examined for the presence of additional morphosyntactic AAE features. Several forms identified in the literature for adults was not observed in our child samples. Accordingly, it was important to examine the current transcripts for the presence of AAE types representative of either older child or adult dialect users. Several summary sources were used to identify additional AAE forms for adults (Dillard, 1972; Fasold \& Wolfram, 1970; Green, 1998; Labov, 1972, 1998; Martin \& Wolfram, 1998; Terrell \& Terrell, 1993; Wolfram, 1971, 1986), and the transcripts were examined for the presence of these forms. Using this methodology, six additional morphosyntactic forms were identified from the transcripts and these are highlighted in the Appendix with an asterisk. A total of 26 morphosyntactic forms were identified and scored across participants.

A dialect density measure (DDM) was calculated for each subject by dividing the number of AAE tokens by the number of words in the overall sample. The DDM was designed to provide a gross measure of morphosyntactic dialect production relative to overall language productivity. This measure was calcu- 
Washington \& Craig: Morphosyntactic forms of African American English

lated relative to numbers of words in the sample because it is possible to produce multiple AAE forms in an utterance. Thus, DDM provided some measure of control for the opportunity to produce dialectal forms (see Craig \& Washington, 2000, for a more detailed discussion of this measure). In addition, samples were examined for the percentage of frequency of occurrence of dialect forms across child and adult samples, as well as within those samples. Individual AAE types were examined for differences in their structure and/or function based on child versus adult status.

\section{Reliability}

Transcription reliabilities were established for each sample. Approximately $10 \%$ of the transcripts were randomly selected and the discourse retranscribed by an independent observer. A point to point comparison for morphemes was $87 \%$ when the number of agreements was divided by the number of disagreements.

Approximately $10 \%$ of the samples were also randomly selected and rescored by an independent observer using the morphosyntactic scoring taxonomy. Point to point comparisons for AAE types and tokens resulted in 86 and $91 \%$ agreement, respectively.

\section{RESULTS}

The participants' language performance provided evidence of both quantitative and qualitative similarities and differences in both general language productivity and dialect usage within and across language samples. The general aspects of language that were used will be discussed for the child and adult participants first, followed by specific quantitative and qualitative aspects of their spontaneous dialectal productions.

\section{General language characteristics}

The spontaneous language samples were successful in eliciting a sizable sample of adult and child speech. A total corpus of approximately 51,000 words was produced for analysis across the 28 samples. The mean frequencies of words produced by the children were examined relative to a number of important covariables, including grade, gender, and SES. No significant differences in the total number of words were apparent by grade or gender (see Table 1). No statistic was run to examine the SES because of the small sample $(N=6)$ of low SES participants. The small sample size decreases the power of any statistic, significantly impacting our ability to detect differences in performance based on income status.

The caregivers' overall production of words $(M=1200.0, S D=456.1)$ was also calculated. Visual inspection of this data suggested that the adults talked significantly more than did their children. A $t$ test for independent samples provided statistical support for these impressions for words, $t(54)=5.79, p<.01$. Visual inspection of the data suggested that no SES differences were apparent in the production of words and utterances for this sample of adult respondents. 
Washington \& Craig: Morphosyntactic forms of African American English

Table 1. Mean numbers of words for child participants by gender, grade, and SES

\begin{tabular}{lc}
\hline \hline & Words \\
& $M(S D)$ \\
\hline Gender & \\
Boy & $551.1(184.4)$ \\
Girl & $723.5(286.4)$ \\
Grade & \\
$\quad$ Preschool & $534.2(108.6)$ \\
Kindergarten & $602.5(225.9)$ \\
First grader & $725.0(315.6)$ \\
SES & \\
$\quad$ Low & $621.2(238.5)$ \\
Middle & $633.9(256.5)$ \\
\hline \hline
\end{tabular}

Note: gender: $t(26)=1.92, p>.05$; grade: $F(2)=1.51 ; p>.05$.

\section{Morphosyntactic dialect characteristics}

Group trends. AAE types and tokens were evident in the language samples of every caregiver and child who participated in this investigation. The mean number of AAE types and tokens produced by the children and caregivers were examined. The children's use of AAE types $(M=7.8, S D=2.5)$ was very similar to the use of these different forms by the adult caregivers $(M=8.0$, $S D=3.3)$. Concerning the total number of AAE tokens, adults $(M=40.7, S D$ $=30.6)$ produced significantly more than the children $(M=27.3, S D=12.7)$. Because the caregivers produced nearly twice as many words overall as the children, it was probable that the increased production of AAE tokens by the adults was influenced by increased opportunity. Pearson correlation coefficients revealed a significant correlation between AAE tokens and number of words produced $(r=.51, p<.001)$, indicating that at least some of the variance in the production of AAE tokens might be explained by the increased amount of talk documented for these caregivers. Calculation of the DDM for the children $(M=$ $.046, S D=0.004)$ and for the caregivers $(M=0.036 ; S D=0.004)$, which controls for opportunity, confirmed that there were no significant quantitative differences in dialect production between the adults and children, $t(54)=1.70, p>.05$.

An examination of the use of specific AAE types across all child and adult samples revealed that three types were particularly prominent, being produced in at least 24 of 28 samples (i.e., $86-100 \%$ of samples) by both children and their caregivers (see Figure 1). Specifically, these three forms were deletion of the copula, deletion of the auxiliary, and subject-verb variation. These findings were consistent with our earlier work that identified these three AAE types as the most frequently used forms for African American children from low and middle SES backgrounds and across varied language sampling contexts (Washington et al., 1998; Washington \& Craig, 1998) who are AAE speakers. The 


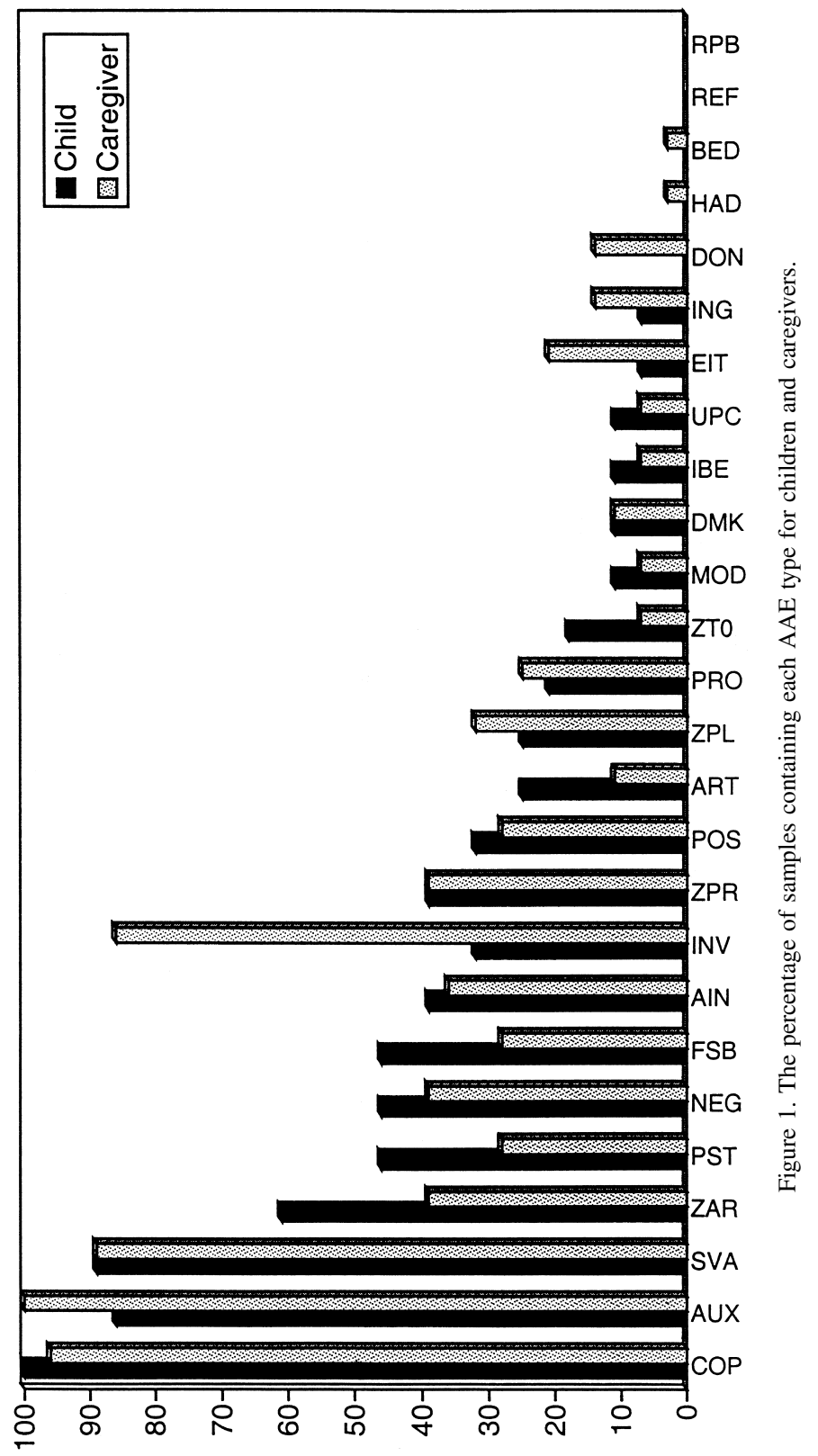


Washington \& Craig: Morphosyntactic forms of African American English

current data indicated that these types are the three most frequently identified across samples for our adult dialect speakers as well.

In addition to these 3 high frequency AAE types, 24 out of $28(86 \%)$ caregivers also produced one additional form, noninverted questions, compared to only $9(32 \%)$ of their children.

There were three AAE types identified in the caregiver samples that were not used by the children: completive done, preterite had, and resultative be done. Interestingly, these forms appeared only sparingly across the adult samples as well, representing the lowest frequency types identified across all samples (see Figure 1). More specifically, only one caregiver provided any examples of resultative be done, four produced completive done, and only one produced preterite had. Two forms, remote past been and regularized reflexive pronoun, were not evident in either the adult or child samples. Interestingly, these latter two AAE types were discussed in Washington and Craig $(1994,1998)$ because they were identified in the productions of children in a school-based language sampling context, despite their absence in the current, home-based context.

The examination of the frequency of occurrence of specific AAE tokens within language samples revealed somewhat similar configurations than those identified for AAE types across samples (see Figure 2). Specifically, the mean number of tokens produced by adults and children were highest for deletion of the copula, subject-verb variation, and deletion of the auxiliary. In addition, noninverted questions were also produced with high frequency by adults.

Individual variation. Although calculating group means was useful for identifying trends in the use of AAE tokens by children and adults, it should be noted that there was a great deal of variability in the production of AAE tokens by individual speakers. By way of example, Figure 3 presents boxplots that illustrate the median (solid line inside the box) and range of token use by adults and children for deletion of the copula, subject-verb variation, deletion of the auxiliary, and by adults for noninverted questions. These plots depict the variability in token use around the median across these four types, as well as the outliers, whose token production was significantly above the sample means. The amount of variability for copula production was particularly striking. The mean number of tokens for adults was $13.89(S D=12.70)$; however, 62 instances of copula deletion were identified for one caregiver. The child of this caregiver was also an outlier with 25 copula deletions.

Aside from this variability in production, which was expected, perhaps the most interesting fact about the dialect profile presented in Figure 2 is that, with the exception of the aforementioned high frequency forms, most morphosyntactic AAE forms are extremely low frequency within both adult and child samples. In a study of dialect produced across multiple interviews, Rickford and McNairKnox (1994) also found that the small number of tokens on which percentages are based for selected AAE types makes it very difficult to document changes in dialect production using statistical measures.

An examination of types within caregiver-child dyads revealed a somewhat less variable distributional pattern than that identified for tokens. In order to facilitate a closer examination of patterns of dialect used by each dyad, the 

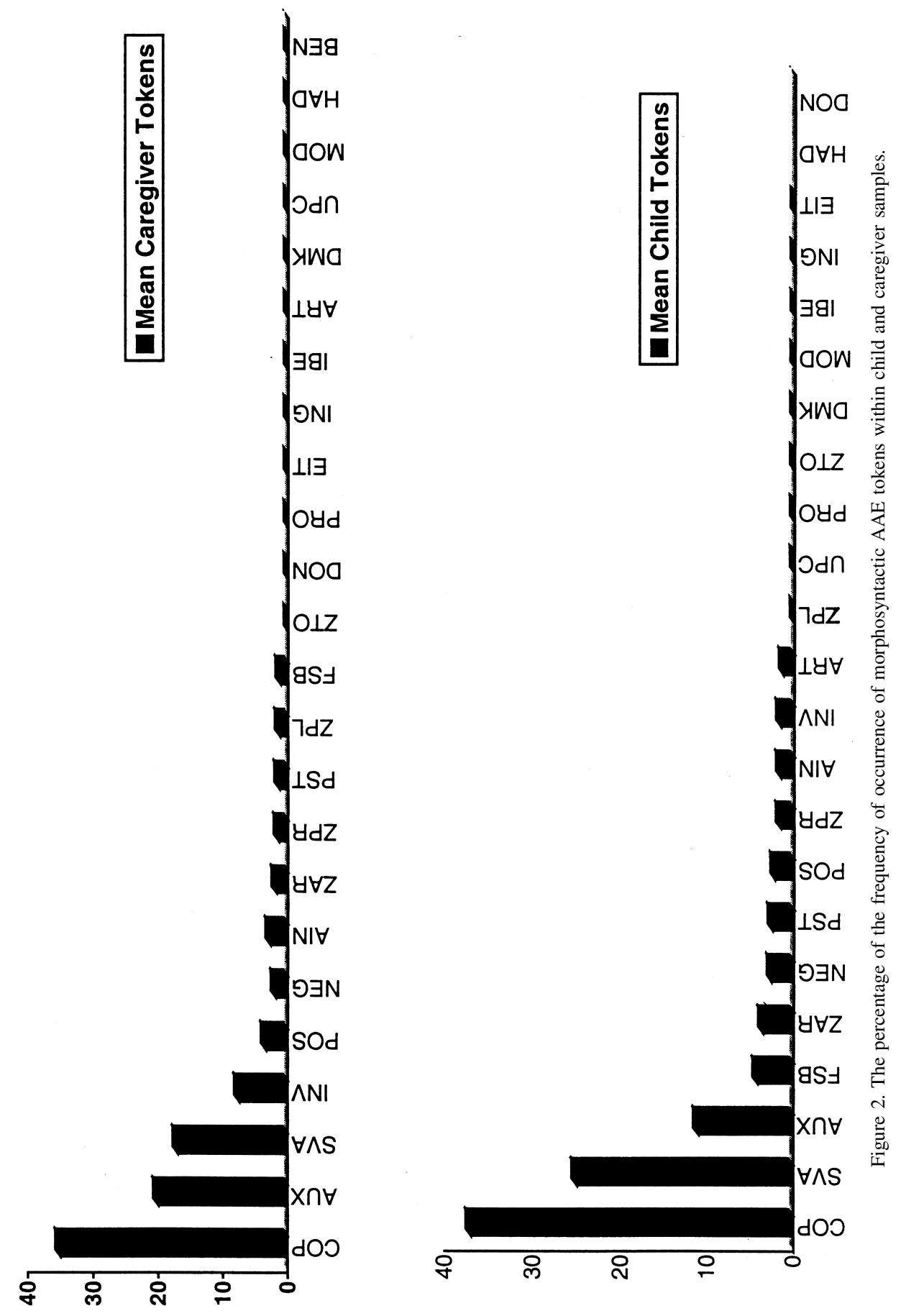

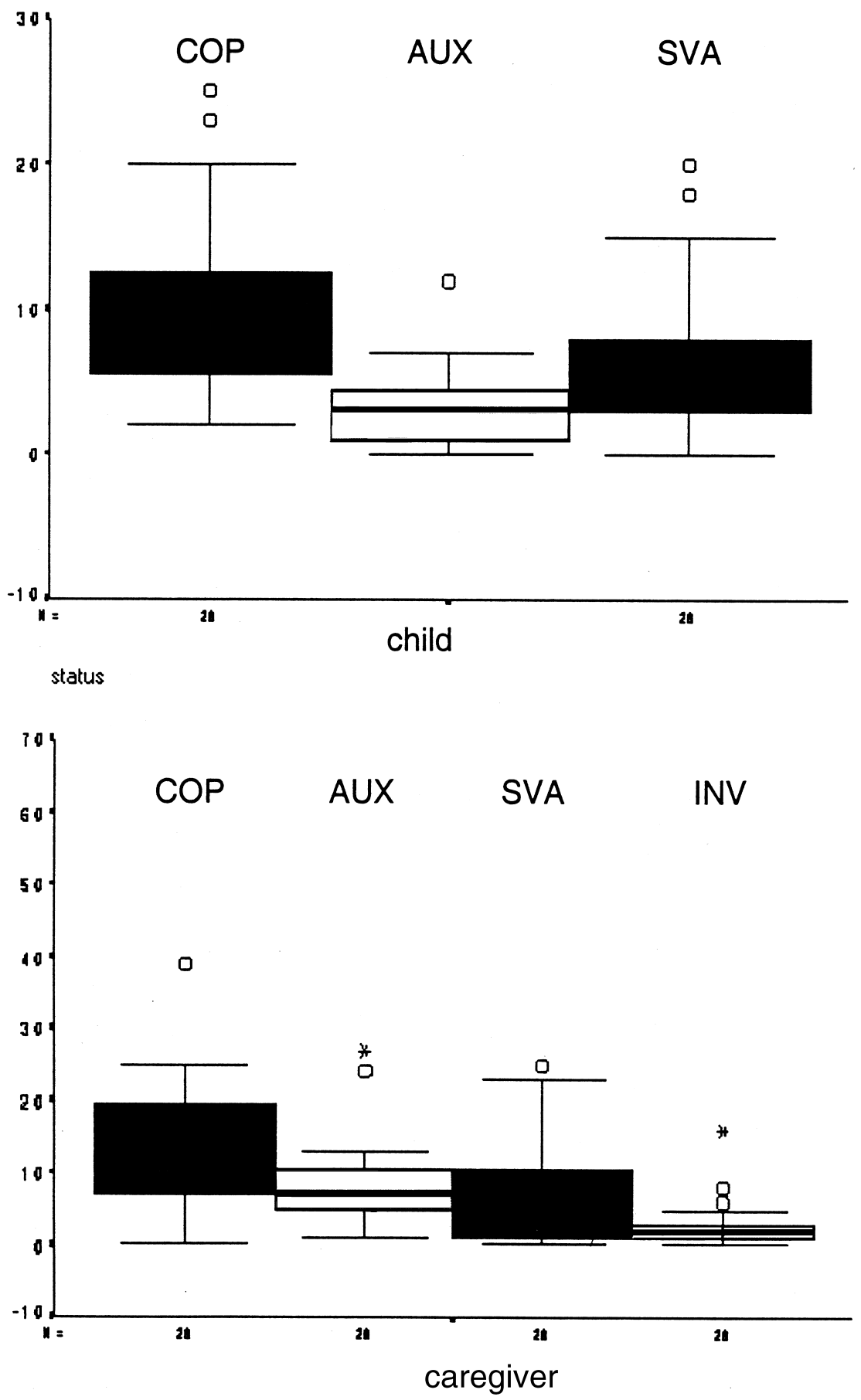

status

Figure 3. Boxplots depicting the variability in high frequency AAE forms for caregivers and children. 
Washington \& Craig: Morphosyntactic forms of African American English

Table 2. Quartile distributions of AAE types for preschool $(P)$, kindergarten $(K)$, and first grade $(F)$ children and caregivers $(C)$

\begin{tabular}{|c|c|c|c|c|c|c|c|}
\hline \multicolumn{2}{|c|}{ First quartile } & \multicolumn{2}{|c|}{ Second quartile } & \multicolumn{2}{|c|}{ Third quartile } & \multicolumn{2}{|c|}{ Fourth quartile } \\
\hline $\begin{array}{c}\text { Child } \\
(M=4)\end{array}$ & $\begin{array}{c}\text { Caregiver } \\
(M=4)\end{array}$ & $\begin{array}{l}\text { Child } \\
(M=5)\end{array}$ & $\begin{array}{l}\text { Caregiver } \\
(M=5)\end{array}$ & $\begin{array}{c}\text { Child } \\
(M=8)\end{array}$ & $\begin{array}{c}\text { Caregiver } \\
(M=7)\end{array}$ & $\begin{array}{l}\text { Child } \\
(M=10)\end{array}$ & $\begin{array}{c}\text { Caregiver } \\
(M=9)\end{array}$ \\
\hline $\mathrm{F} 1$ & CK2 & $\mathrm{K} 2$ & $\mathrm{CF}^{*} *$ & $\mathrm{P}^{*} *$ & CF9 & F9 & $\mathrm{CP} 2$ \\
\hline \multirow[t]{9}{*}{ K1 } & $\mathrm{CF} 2$ & P1 & CF7 & $\mathrm{P} 7 *$ & $\mathrm{CP} 1$ & $\mathrm{~F} 10 *$ & CF9* \\
\hline & CF11 & $\mathrm{P} 2$ & CK5 & F6* & CP6* & F11 & CK3 \\
\hline & $\mathrm{CF} 4$ & $\mathrm{~F} 2$ & CP5* & F7 & CP7* & K6* & CK4 \\
\hline & CP4 & F3* & CP8 & F8* & CF6 & K7* & CK6* \\
\hline & & $\mathrm{F} 4$ & & K3 & CF1 & K8* & CK7* \\
\hline & & P3 & & K4 & CF8* & $\mathrm{K} 9 *$ & CK8* \\
\hline & & P4 & & K5 & CK1 & & CK9* \\
\hline & & $\mathrm{P} 5 *$ & & P8 & $\mathrm{CP} 3$ & & CF5 \\
\hline & & F5 & & & & & \\
\hline
\end{tabular}

Note: F1, first grader \#1; F2, first grader \#2; CF1, caregiver for first grader \#1; etc. The mean $(M)$ values are the number of types.

*The corresponding performance with the caregiver.

number of AAE types used by each caregiver-child pair was calculated, subdivided into quartiles, and examined for similarities or differences in distribution using the Statistical Package for the Social Sciences (SPSS; see Table 2). Table 2 illustrates the distribution of types for the children and their caregivers, highlighting the children and caregivers whose production of AAE types represented performance in the same quartiles. This distributional correspondence was evident for 11 caregiver-child pairs (39\%). In particular, children whose performance placed them in the highest (fourth) quartile were most likely to have parents whose use of AAE types was also at this high level. Specifically, 71\% of these children $(N=5)$ also had parents whose token use placed them in the top quartile. Conversely, for the two children in the lowest quartile, none had parents whose use of types was also in the first quartile. In fact, the parents of these children produced more than twice as many AAE types as their children. The replication of this quartile distribution for tokens revealed similar outcomes. All the caregiver-child pairs whose use of AAE types placed them in the fourth quartile were also in this highest group for token use. Interestingly, although parents of the two children who were in the first quartile for use of types produced twice as many types as their children, their use of AAE tokens was in the first quartile, corresponding to their childrens' token production.

Differences in caregiver-child patterns. In order to identify differences in use of AAE types that might be indicative of generational changes, each participant's dialectal variations were examined individually. Eight AAE types showed remarkable differences in distribution, function, and/or structure for children compared to caregivers: zero copula, noninverted questions, multiple negation, 
Washington \& Craig: Morphosyntactic forms of African American English

zero possessive, ain't, appositive pronoun, zero to, and undifferentiated pronoun case.

ZERO COPULA. This high frequency AAE type differed relative to the copula structure used most frequently by adults and children. Adult samples evidenced 396 instances of copula deletion, and children evidenced 277 instances. In the children more than half (53\%) of the utterances scored for zero copula involved the deletion of third person is (e.g., "this the mattress"), $38 \%$ involved deletion of the second person or plural are (e.g., "they going to the beach"), and the remainder (9\%) consisted of first person am deletions. By contrast, in the caregivers $72 \%$ of copula deletions involved second person or plural are constructions (e.g., "they gonna pretend like it's summer") and less than one-third (27\%) involved the deletion of third person is (e.g., you know he gonna fall"). First person deletions were rare (1\%) for adults. In other words, there appeared to be a marked preference for are deletions among adults and is deletions among children. Rickford and colleagues (1991) reported similar distributional differences between teenage AAE speakers and their parents and elderly dialect speakers. Copula deletion, on average, was much higher frequency for their adolescent speakers compared to the middle and older speakers, and the same preference for is deletions was apparent for their teenage informants as well.

NONINVERTED QUESTIONS. A further analysis of noninverted questions revealed differences in the structure and the conversational function of these requests for the caregivers and children. Structurally, the majority (86\%) of caregivers uses of noninverted questions included pronominal, referential subjects in the sentence initial position, followed by a main or auxiliary verb form. The requesting or questioning nature of these utterances was evident only in the rising intonation used by the adult speakers. Some examples of these follow:

1. It's gonna be a surprise?

2. That's their little house?

3. They can disappear in smoke?

Noninverted questions involving wh- question words (who, what, when, where, how) were rare for adults, constituting only $6 \%$ of utterances in this category. For children, however, most of these utterances (64\%) did include whquestion words, as follows:

1. Where the french fries are going?

2. Why they're sleeping?

The remainder of the children's uses took the adult form.

Functionally, there were differences apparent in the conversational use of noninverted questions for adults and children. Using Garvey (1977) and Dore's (1978) conversational analysis categories for requests, many of the caregiver's noninverted questions could be characterized as specific requests for confirmation (RQCON, 46\%) or specific requests for information (RQIN, 29\%). Exam- 
Washington \& Craig: Morphosyntactic forms of African American English

Table 3. Request definitions and examples for caregiver and child noninverted questions

\begin{tabular}{ll}
\hline \hline Definition & \\
\hline RQIN: Unsolicited requests seeking spe- & CHI: "What the monster did?" \\
cific factual information & ADU: "What else we can play?" \\
RQCON: Unsolicited requests seeking & CHI: "Cher goes here?" (confirming place- \\
confirmation of a previous utterance or & ment of doll in game configuration) \\
action & ADU: "He's sposeta go down the pipe \\
& and into the slime?" \\
\hline \hline
\end{tabular}

Tag questions were not included in these scoring categories.

ples and definitions of each are provided in Table 3. All of the children's noninverted questions fell into these categories as well (RQCON, 21\%; RQIN, 79\%), although the distribution of the categories was very different than that identified for the caregivers. Most of the childrens' uses involved sincere requests for information from the adult, whereas nearly half of the adults' productions sought to confirm a rule in the game(s) being played or the appropriate use of an object in the game.

In addition, a third category was identified for the adult use of noninverted forms that was not apparent for their children. More than one-third (37\%) of adult utterances could be described as other-initiated repairs (Levinson, 1983; Schegloff, 2000). Following are two examples of exchanges containing these repair sequences:
Example 1
Example 2
ADU: What do you call this?
ADU: One can sit.
CHI: It's for the pizza.
CHI: No he's the bad guy.
ADU: That's the tray to take the pizza?*
ADU: This is the bad guy?*
CHI: yeah.
ACU: This is not a guy it's a ...
ADU: OK.
CHI: It's a turtle person.

Levinson describes examples such as the asterisked utterances above as next turn repair initiators. As the name suggests, these utterances "invite repair of the prior turn in the next turn" (Levinson, 1983, p. 339) and are distinguished by the initiation of the repair by someone other than the speaker of the repairable utterance. Repairs may take many forms, including word recovery, self-corrections, and, in this case, corrections initiated by the listener. The differences in frequency of use of this AAE form appeared to be largely governed by differences in its discourse function for the children and adults in this study, and these differences appeared to be related to the parent's authority role in the conversational interaction.

MULTIPLE NEGATION. In the adults the majority of utterances (75\%) involving multiple negation took the following form: contracted negative modal auxiliary can't, won't, or don't plus a second negative: 
Washington \& Craig: Morphosyntactic forms of African American English

1. You can't sit nobody on there

2. I don't think neither one of these fit on here.

3. So there won't be no kids there?

The remaining $25 \%$ of the multiple negative constructions were formed by combining not, isn't, or ain't with a second negative form (e.g., "they're not going nowhere"). In contrast, more than half of the childrens' multiple negatives $(54 \%)$ were formed by combining the earlier forms not and ain't with a second negative and $45 \%$ involved the use of the more mature modal auxiliaries to construct the negative sentence.

ZERO POSSESSIVE. Deletion of the possessive can be accomplished in AAE by deleting the possessive marker -s (e.g., "mommy house") or by using the nominative or objective case of pronouns in place of the possessive form (e.g., "I went to they house). The use of one possessive AAE form or the other differed markedly for the children and caregivers. In the children $47 \%$ of utterances involving zero possession were formed by deleting the -s marker, whereas slightly more than half (53\%) involved the use of the nominative or objective case in place of the possessive pronoun. In contrast, zero possession, which involves deletion of the $-\mathrm{s}$ marker, accounted for only $3 \%$ of adult productions. The other $97 \%$ were produced using the pronominal form, which was most frequently expressed as they/their (e.g., "what do they like to eat on they pizza?").

AIN'T. Examples of ain't used to form tag questions were evident for the caregivers, but not for children (e.g., "he's the smart one, ain't he?"). This use of ain't was low frequency even for adults, comprising only $18 \%$ of their ain't constructions. Although children at the age of the participants in this study can, and did, produce tag questions in their samples, ain't was never used to form such questions. All other ain't productions for both adults and children involved the use of ain't as a negative auxiliary (e.g., "she ain't wearing a sweater") or a main verb (e.g., "Mama, I ain't ready").

APPOSITIVE PRONOUN. Caregiver uses of this AAE type included the addition of parenthetical noun phrases as a part of the appositive pronoun structure.

1. Wilma and Betty, do they bowl, too?

2. Some of this junk food, I don't know what's in it.

On the surface, these utterances were most salient for the distance from the parenthetical segment to the pronoun that referred to it. In contrast, the following types of appositive constructions, in which the noun subject was also parenthetic but was adjacent to the pronoun referent, were most prevalent for the children:

1. Raphael he gonna push this.

2. Mikey he's a bozo.

3. Ninja Turtle they don't fight each other. 
Interestingly, the only child who produced an appositive pronoun similar in form to the adults ("Me and Simone, we made up this little song") was a first grade girl, who was among the oldest participants in this investigation.

ZERO TO. The zero to construction was remarkable for the restrictive context within which caregivers seemed able to delete the to in infinitival structures, compared to its less restricted use by the children. Specifically, sentences in which zero to was scored for adults were questions containing the main verb want followed by an infinitive ( $98 \%$ of the time). The following utterances illustrate the adult form ${ }^{1}$ :

1. You want me have him?

2. You want me dress him?

3. So you want me take this off?

Conversely, childrens' productions showed no such clear production rule, appearing to be much more varied in its application:

1. They're going go and get busy.

2. You didn't give me a turn have this.

3. That's for them go down when they get on top of the house.

In fact, the constructions containing want were not at all evident in the childrens' use of zero to.

UNDIFFERENTIATED PRONOUN CASE. Like zero to, this AAE type was notable for the restricted context identified for its use by adults compared to its use by children. Adult use of undifferentiated pronoun case was restricted to the substitution of the objective pronoun them for those, as in the example "Them turtles ain't got no furniture man." For children, them/those structures were evident as well: "I don't like them bad people." In addition, children substituted object pronouns for subject pronouns. Several examples involving her/she were identified, as in the example "her needs some pants too." Him/he was also identified, as in the example "Him up here." Of all the differences identified between child and adult use of AAE, the difference in use of the undifferentiated pronoun case between children and their caregivers appeared most "childlike." Thus, we were not surprised to find that adults did not produce these constructions.

\section{DISCUSSION}

This descriptive account of the AAE used by young children and their caregivers revealed several interesting trends for consideration. Perhaps most notable were similarities in the overall frequency of occurrence and distribution of AAE types for children and their caregivers. In particular, the density of dialect produced by caregivers and children and the features most prevalent in their discourse were strikingly similar. The density with which AAE types appear in an individ- 
ual speaker's spontaneous productions can vary widely, even within the same geographic communities (Washington \& Craig, 1994, 1998). However, in the case of these caregivers and children, the density was very similar.

Children who used the widest variety of types were found to be most similar to their parents in their quantitative use of AAE. These children and their caregivers not only produced many different types but also produced tokens at a level that placed them in the highest quartile for token use. Washington and Craig (1994, 1998) demonstrated with young children that these AAE speakers, termed high dialect users, do not simply use the same types over and over again. Rather, they exhibit a skillful use of a wide variety of dialect forms. That finding was supported by the children and caregivers in this investigation.

It will be interesting to determine in future studies if the similarities in dialect usage by young children and caregivers represent learned dialectal patterns that are transferred from caregiver to child. Conversely, these similarities may represent the childrens' sensitivity to the communication style of a given speaker or to other changes in the interactive context. In this case, an explicit shift in dialect use influenced by the communicative context, including different speakers, should occur. The latter explanation would have interesting implications for the study of code shifting in AAE, and those children who produce AAE in the highest quartile may be the most interesting to pursue.

These findings of relative synchrony in the dialect used by young children and their parents contrast with those reported for adolescents whose dialectal variations were compared to adult dialect users (Rickford 1991, 1992; Rickford \& Theberge Rafal, 1996). Adolescents reportedly produced significantly more dialectal variations than adults. The differences in dialect use for these older children are most frequently explained relative to peer identification and expression of ethnic identity by teenagers. Those factors have little influence if any at the young ages of the participants in this investigation. For young children the primary social and language influences are presumably the caregivers and the child's immediate family. The use of dialect by children and adults in this study appeared to reflect that relationship. Most differences in dialect use seemed to reflect the childrens' developing linguistic skills rather than any identification with factors external to the home or linguistic community.

The exceptions, of course, were in the production of zero copula and noninverted questions. The distribution of is and are deletion for zero utterances in our young subjects was very similar to that reported by Rickford et al. for adolescents. However, it is not entirely clear which factors influence this apparent preference for $i s$ forms in young dialect speakers. Differences in the distribution and use of noninverted questions were driven by their discourse functions and appeared to be related to the mother's role as authority in the play interaction rather than any specific cultural or dialectal factors. This AAE form assumed a function in discourse that was previously reported in studies of motherchild interactions and supported Blake's (1994) conclusion that forms used by African American caregivers for expressing selected conversational functions may vary from White mothers, although the functions remain similar. Attention to the contribution that discourse analysis may provide for understanding differences in use of specific types will be important in future studies of AAE. 
In our previous investigations we found the same three forms, zero copula, zero auxiliary, and subject-verb variation, to be of the highest frequency for all AAE speakers, regardless of grade, SES, gender, or data collection context (Washington et al., 1998; Washington \& Craig, 1994, 1998). This study extends this finding to include adult AAE speakers, as well as an additional language sampling context. It appears that if an individual is a speaker of AAE, we can expect that these three features will be evident in his or her spontaneous discourse.

Although no SES differences were apparent for our caregivers and children, this was likely influenced by the small number of low SES families who agreed to participate. As a result, this was largely a middle SES sample. This is an important caveat because other studies of dialect variation reported differences in dialect use by SES. It would be interesting to know if the adult-child patterns of dialect use reported here will be documented for children from low income families as well.

Finally, this investigation demonstrates the usefulness of caregiver-child interactions for examining and interpreting the dialectal productions of young African American children. The caregivers and children in this study exhibited many similarities, as well as differences, in the use of dialect overall and in the use of specific dialect structures. These comparisons should be useful for interpreting the young child's dialect use compared to that of the larger AAEspeaking community. The extant literature provides examples of adolescent dialect use for comparison as well. A comparison of Rickford et al.'s outcomes to those reported here suggests that the adolescent dialect speaker is in a state of transition relative to dialect use. The adolescent preference for is deletion is similar to our young subjects and differs from adults, whereas the significantly increased use of dialect for adolescents compared to adults does not characterize young children. It appears that the adolescent state of transition is as evident in their linguistic forms as it is in other aspects of their development. It will be important then to examine AAE use across childhood to determine when or if young childrens' dialect progresses toward the dialect use identified for adolescents and when or if adolescent use converges with adult use. The outcomes of this investigation highlight the need to study dialectal patterns of children, both young and old, in their own right. 
Applied Psycholinguistics 23:2

Washington \& Craig: Morphosyntactic forms of African American English

\section{APPENDIX}

The morphosyntactic AAE forms scored for each child and adult subject

\begin{tabular}{|c|c|}
\hline Definition & Examples \\
\hline \multicolumn{2}{|l|}{ Ain't (AIN)* } \\
\hline \multirow{3}{*}{$\begin{array}{l}\text { ain't used as a negative auxiliary in } \\
\text { have }+ \text { not, do }+ \text { not, are }+ \text { not, and is } \\
+ \text { not constructions }\end{array}$} & "You ain't gonna play like that." \\
\hline & "I ain't seen that thing." \\
\hline & $\begin{array}{l}\text { "They ain't make these things for Barbie } \\
\text { when I was little." }\end{array}$ \\
\hline \multicolumn{2}{|l|}{ Indefinite Article (ART) } \\
\hline $\begin{array}{l}\text { article } a \text { used regardless of vowel } \\
\text { context }\end{array}$ & $\begin{array}{l}\text { "Brandon had to play for a hour, didn't } \\
\text { he?" }\end{array}$ \\
\hline \multicolumn{2}{|l|}{ Zero Auxiliary (AUX) } \\
\hline modal auxiliary forms will, can, do, & “ you have another one?" \\
\hline and have variably included & "I __ get you a shake." \\
\hline \multicolumn{2}{|l|}{ Resultative be done (BED)* } \\
\hline $\begin{array}{l}\text { "be done" used in the future perfect } \\
\text { tense }\end{array}$ & $\begin{array}{l}\text { "We be done dropped these and broke } \\
\text { them." }\end{array}$ \\
\hline \multicolumn{2}{|l|}{ Zero copula (COP) } \\
\hline is, are, am, and other forms of the verb & "The bridge _ out." \\
\hline $\begin{array}{l}\text { to be variably included in either copula } \\
\text { or auxiliary form }\end{array}$ & "They__ not finished eatin' yet." \\
\hline \multicolumn{2}{|l|}{ Double marked "s" (DMK)* } \\
\hline hypercorrection of irregular plural and & "You have all these mens." \\
\hline possessive constructions & "This one is like mines." \\
\hline \multicolumn{2}{|l|}{ Completive done (DON)* } \\
\hline done is used for emphasis to make ref- & "We done lost the head." \\
\hline $\begin{array}{l}\text { erence to an action completed in the re- } \\
\text { cent past }\end{array}$ & "I think we done ate enough." \\
\hline \multicolumn{2}{|l|}{${\underline{\text { Existential it }(\mathrm{EIT})^{*}}}^{*}$} \\
\hline $\begin{array}{l}\text { it used in place of there to indicate the } \\
\text { existence of a person, place, or thing } \\
\text { without adding referential meaning }\end{array}$ & $\begin{array}{l}\text { "It seems it's a lot more on here that you } \\
\text { haven't shown me." }\end{array}$ \\
\hline \multicolumn{2}{|l|}{ Fitna/Sposeta/Bouta (FSB) } \\
\hline abbreviated forms of "fixin' to," “sup- & "He bouta fall off this." \\
\hline $\begin{array}{l}\text { posed to," "and about to," coding immi- } \\
\text { nent action }\end{array}$ & "I'm fitna call." \\
\hline \multicolumn{2}{|l|}{$\mathrm{Had}_{(\mathrm{HAD})}^{*}$} \\
\hline $\begin{array}{l}\text { preterite had before the verb in simple } \\
\text { past constructions }\end{array}$ & "You had got his toes stuck before." \\
\hline \multicolumn{2}{|l|}{ Zero -ing (ING) } \\
\hline $\begin{array}{l}\text { present progressive -ing variably in- } \\
\text { cluded }\end{array}$ & "What are you lay_ in the sun for?" \\
\hline \multicolumn{2}{|l|}{ Invariant be (IBE) } \\
\hline $\begin{array}{l}\text { infinitival be coding habitual action } \\
\text { with a variety of participants }\end{array}$ & $\begin{array}{l}\text { "It don't be gettin' in the way when they } \\
\text { be drivin'?" }\end{array}$ \\
\hline \multicolumn{2}{|l|}{ Double modal/double auxiliary (MOD)* } \\
\hline $\begin{array}{l}\text { two modal auxiliary forms used in a } \\
\text { single clause }\end{array}$ & $\begin{array}{l}\text { "I might can." (adult) } \\
\text { "I'm is the last one ridin" on." (child) }\end{array}$ \\
\hline
\end{tabular}


Washington \& Craig: Morphosyntactic forms of African American English

\section{APPENDIX (cont.)}

\begin{tabular}{lc}
\hline \hline Definition & Examples \\
\hline
\end{tabular}

Multiple negation (NEG)

two or more negative markers in one utterance

Zero possessive (POS)

possession coded by word order so that

(a) possessive $-s$ marker is deleted or

(b) nominative or objective case of pronouns is used rather than possessive

Appositive Pronoun (PRO)

both a pronoun and a noun or two pronouns used to reference the same person or object

Zero past tense (PST) marker -ed not always used to denote regular past constructions or the present tense form used in place of the irregular past form

Reflexive Pronoun (REF)

reflexive pronouns "himself" and

"themselves" expressed as "hisself" and "theyself" or "theirselves"

Remote past been (BEN)

"been" used to mark action in the remote past

Undifferentiated pronoun case (UPC) nominative, objective, and demonstrative cases of pronouns used interchangeably

Subject-Verb Variation (SVA) the subject and verb in a (a) first, (b) second, or (c) third person plural or singular construction differing in either number or person

Zero article (ZAR) the definite article "the" and indefinite articles "a" and "an" variably included

Zero plural (ZPL)

the plural marker $-s$ variably included

Zero preposition (ZPR)*

prepositions of, on, and at variably included
'I don't remember nobody havin' no motorcycle in the movie."

(a) "This go in Barbie_kitchen."

(b) "They gettin' they technique together."

"I mean who(se) is this?

"We need to find us one pizza yesterday." "Barbie she goin' to work."

"He punch _ me in the stomach."

"And then them fall."

"He stands by hisself."

"I been knowing how to swim."

“Them not goin' to go."

(a) "I gets too hot."

(b) "I knew you was gonna say that."

(c) "The rest of them was yours."

"Now _ food is ready."

"You know I got 2 Ninja Turtle tape ."

"Hey get out the way."

"What you gonna do the weekend?"

"Least he's matching." 
Washington \& Craig: Morphosyntactic forms of African American English

APPENDIX (cont.)

\begin{tabular}{ll}
\hline \hline Definition & \multicolumn{1}{c}{ Examples } \\
\hline Zero to (ZTO) & \\
\hline infinitive marker to variably included & "I don't know how _ do it though." \\
$\begin{array}{l}\text { Noninverted Questions (INV) } \\
\text { subject and auxiliary not inverted in di- "What we can do?" } \\
\text { rect questions, including those involv- } \\
\text { ing wh- forms }\end{array}$ & "That's how it go?" \\
\hline \hline
\end{tabular}

*New features identified from mother-child samples.

\section{NOTE}

1. The adult constructions containing zero to were also notable for their use of dative pronominal reference. Personal dative structures were evident in nonquestion form for both adults (e.g., "You can make you a roast beef sandwich") and children (e.g., "I got me a baby"). These structures, although considered nonstandard, are typically associated with regional dialects such as southern dialects of American English, rather than with African American speakers (Martin \& Wolfram, 1998; SchillingEstes \& Wolfram, 1998). Consequently, although they were not included in the list of AAE features examined here, they were coded in the transcripts as examples of nonstandard English usage.

\section{REFERENCES}

Anderman, C., Cheadle, A., Curry, S., \& Diehr, P. (1995). Selection bias related to parental consent in school-based survey research. Evaluation Review, 19, 663-674.

Bailey, G., \& Maynor, N. (1989). The divergence controversy. American Speech, 64, 12-39.

Battle, D. E. (1993). Introduction. In D. E. Battle (Ed.), Communication disorders in multicultural populations (pp. xv-xxiv). Boston: Andover Medical Publishers.

Black, B., \& Logan, A. (1995). Links between communication patterns in mother-child, fatherchild, and child-peer interactions and children's social status. Child Development, 66, 255271.

Blake, I. K. (1993). The social-emotional orientation of mother-child communication in African American families. International Journal of Behavioral Development, 16, 443-463.

Blake, I. K. (1994). Language development and socialization in young African-American children. In Patricia M. Greenfield (Ed.), Cross-cultural roots of minority child development. Hillsdale, NJ: Erlbaum.

Bloom, L., Rocissano, L., \& Hood, L. (1976). Adult-child discourse: Developmental interaction between information processing and linguistic interaction. Cognitive Psychology, 8, 521552

Choi, S. (2000). Caregiver input in English and Korean: Use of nouns and verbs in book-reading and toy-play contexts. Journal of Child Language, 27, 69-96.

Craig, H. (1996). The challenges of conducting language research with African American children. In A. G. Kamhi, K. E. Pollock, \& J. L. Harris (Eds.), Communication development and disorders in African American children (pp. 1-17). Baltimore: Brookes Publishing.

Craig, H. K., \& Washington, J. A. (2000). An assessment battery for identifying language impairments in African American children. Journal of Speech-Language-Hearing Research, 43, 366-379.

Cross, T. (1977). Mother's speech adjustments: The contribution of selected child-listener variables. In C. Snow \& C. Ferguson (Eds.), Talking to children: Language input and acquisition. Cambridge: Cambridge University Press. 
Delain, M., Pearson, D. P., \& Anderson, R. C. (1985). Reading comprehension and creativity in Black language use: You stand to gain by playing the sound game! Amercian Educational Research Journal, 22, 155-173.

Delpit, L. (1995). Other people's children: Cultural conflict in the classroom. New York: New Press.

Dillard, J. (1972). Black English. New York: Random House.

Dore, J. (1978). Requestive systems in nursery school conversations: Analysis of talk in its social context. In R. Campbell, \& R. P. Smith (Eds.), Recent advances in the psychology of language: Language and mother-child interaction. New York: Plenum Press.

Ellickson, P. L., \& Hawes, J. A. (1989). An assessment of active versus passive methods for obtaining parental consent. Evaluation Review, 13, 45-55.

Fasold, R. W., \& Wolfram, W. (1970). Some linguistic features of Negro dialect. In R. W. Fasold \& R. W. Shuy (Eds.), Teaching standard English in the inner city (Vol. 6, pp. 41-86). Washington, DC: Center for Applied Linguistics.

Garvey, C. (1977). The contingent query: A dependent act of communication. In M. Lewis, \& L. Rosenblum (Eds.), Interaction, conversation and the development of language (pp. 63-94). New York: Wiley.

Gleitman, L., Newport, H., \& Gleitman, H. (1984). The current status of the motherese hypothesis. Journal of Child Language, 11, 43-79.

Green, L. (1998). Aspect and predicate phrases in African-American vernacular English. In S. S. Mufwene, J. R. Rickford, G. Bailey, \& J. Baugh (Eds.), African American English: Structure, history, and use (pp. 37-68). London: Routledge.

Hedges, L. V., \& Nowell, A. (1998). Black-White test score convergence since 1965. In C. Jenks \& M. Phillips (Eds.). The Black-White test score gap (pp. 149-181). Washington, DC: Brookings Institutional Press.

Labov, W. (1966). The social stratification of English in New York City. Washington, DC: Center for Applied Linguistics.

Labov, W. (1970). The Study of Nonstandard English. Champaign, IL: National Council of Teachers of English.

Labov, W. (1972). Language in the inner city. Philadelphia: University of Pennsylvania Press.

Labov, W. (1981). What can be learned about change in progress from synchronic description? In D. Sankoff \& H. Cedergren (Eds.), Variation omnibus (pp. 177-199). Carbondale, IL: Linguistic Research.

Labov, W. (1998). Co-existent systems in African American English. In S. S. Mufwene, J. R. Rickford, G. Bailey, \& J. Baugh (Eds.), African American English: Structure, history, and use (pp. 110-153). London: Routledge.

Levinson, S. C. (1983). Pragmatics. Cambridge: Cambridge University Press.

MacWhinney, B. (1994). The CHILDES project: Tools for analyzing talk (2nd ed.). Hillsdale, NJ: Erlbaum.

Martin, S., \& Wolfram, W. (1998). The sentence in African American English. In S. S. Mufwene, J. R. Rickford, G. Bailey, \& J. Baugh (Eds.), African American English: Structure, history and use (pp. 11-36). London: Routledge.

Menyuk, P. (1988). Language development: Knowledge and use. New York: Harper Collins.

Menyuk, P. (1992). Early communicative and language behaviors. In J. Rosenblith (Ed.), In the beginning: Development from conception to age two. Newbury Park, CA: Sage.

Menyuk, P., Liebergott, J. W., \& Schultz, M. C. (1995). Early language development in full-term and premature infants. Hillsdale, NJ: Erlbaum.

Mufwene, S. S., Rickford, J. R., Bailey, G., \& Baugh, J. (1998). African American English: Structure, history, and use. London: Routledge.

Murray, A. D. \& Hornbaker, A. V. (1995). Maternal directive and facilitative interaction styles: Associations with language and cognitive development of low risk and high risk toddlers. Development and Psychopathology, 9, 507-516.

Ramey, C. T., Farran, D. C., \& Campell, F. A. (1979). Predicting IQ from mother-infant interactions. Child Development, 50, 804-814.

Rickford, J. (1992). Grammatical variation and divergence in Vernacular Black English. In M. Gerritsen \& D. Stein (Eds.), Internal and external factors in syntactic change. New York: Mouton de Gruyter. 
Washington \& Craig: Morphosyntactic forms of African American English

Rickford, J., Ball, A., Blake, R., Jackson, R., \& Martin, N. (1991). Rappin on the copula coffin: Theoretical and methodological issues in the analysis of copula variation in African American Vernacular English. Language Variation and Change, 3, 103-132.

Rickford, J., \& McNair-Knox, F. (1994). Addressee- and topic-initiated style shift. In D. Biber \& E. Finegan (Eds.), Sociolinguistic perspectives on register. New York: Oxford University Press.

Rickford, J., \& Theberge Rafal, C. (1996). Preterite had t v-ed in the narratives of African-American preadolescents. American Speech, 71, 227-254.

Schegloff, E. A. (2000). When "others" initiate repair. Applied Linguistics, 21, 205-243.

Schilling-Estes, N., \& Wolfram, W. (1998). American English. Malden, MA: Blackwell.

Seymour, H. N., Bland-Stewart, L., \& Green, L. J. (1998). Difference versus deficit in child African American English. Language, Speech and Hearing Services in Schools, 29, 96-108.

Smitherman, G. (1998). Word from the hood: The lexicon of African-American Vernacular English. In S. S. Mufwene, J. R. Rickford, J. Baugh, \& G. Bailey (Eds.), African American English: Structure, history, and use. London: Routledge.

Terrell, S. L., \& Terrell, F. (1983). African-American Cultures. In D. E. Battle (Ed.), Communication disorders in multicultural populations (pp. 3-37). Boston: Andover Medical Publishers.

United States Department of Agriculture. (1999). Child nutrition programs - Income eligibility guidelines. Federal Register, 64(63)

Wallace, I. F., Roberts, J. E., \& Lodder, D. E. (1998). Interactions of African American infants and their mothers: Relations with development at 1 year of age. Child Development, 41, 900-912.

Washington, J. A. (1996). Issues in assessing the language abilities of African American children. In A. G. Kamhi, K. E. Pollock, \& J. L. Harris (Eds.), Communication development and disorders in African American children (pp. 19-34). Baltimore: Paul H. Brookes Publishing Co.

Washington, J. A., \& Craig, H. K. (1994). Dialectal forms during discourse of poor, urban, African American preschoolers. Journal of Speech and Hearing Research, 37, 816-823.

Washington, J. A., \& Craig, H. K. (1998). Socioeconomic status and gender influences on children's dialectical variations. Journal of Speech, Language and Hearing Research, 41, 618-626.

Washington, J. A., Craig, H. K., \& Kushmaul, A. J. (1998). Variable use of African American English across two language sampling contexts. Journal of Speech, Language and Hearing Research, 41, 1115-1124.

Weinberger, D. A., Tublin, S. K., \& Ford, M. E. (1990). Preadolescents' social-emotional adjustment and selective attrition in family research. Child Development, 61, 1374-1386.

Wolfram, W. (1971). Black and white speech differences revisited. In W. Wolfram \& N. H. Clarke (Eds.), Black-White speech relationships (pp. 139-161). Washington, DC: Center for Applied Linguistics.

Wolfram, W. (1986). Language variation in the United States. In O. L. Taylor (Ed.), Nature of communication disorders in culturally and linguistically diverse populations (pp. 73-115). San Diego, CA: College-Hill Press.

Wolfram, W. (1987). Are Black and White vernaculars diverging? American Speech, 62, 40-48.

Wolfram, W. (1994). The phonology of a sociocultural variety: The case of African American Vernacular English. In J. Bernthal \& N. Bankston (Eds.), Child phonology: Characteristics, assessment and intervention with special populations. New York: Thieme.

Wolfram, W., \& Fasold, R. (1974). The study of social dialects in American English. Englewood Cliffs, NJ: Prentice-Hall. 